\title{
Is gene activation in brain neurons the basis of memory and learning?
}

\author{
ALOIS KNÜSEL, RITA HEIDELBERGER, and CLIVE C. KUENZLE \\ Department of Pharmacology and Biochemistry, School of Veterinary Medicine \\ University of Zürich, Winterthurerstr. 260, CH-8057, Zürich, Switzerland
}

\begin{abstract}
Chromatin was isolated from neuronal nuclei derived from the cerebral cortices of rats raised either in a super-enriched environment or in standard laboratory cages. In order to assess the genetic activity of the neurons from both sources, chromatin preparations from intellectually stimulated and control rats were compared with respect to melting profile and template activity for exogenous RNA polymerase. Using both these parameters, no evidence for increased genetic activity in neurons during learning was obtained.
\end{abstract}

Considerable effort has been directed at finding evidence for the hypothesis that the storage of memory is subserved by chemical coding mechanisms (Glassman, 1969). Despite many such attempts, the notion has remained largely speculative. An attractive proposal, recently put forward by Bonner (1972), invokes gene activation in brain neurons as the molecular basis of memory and learning. The theory suggests that intellecutal information is contained in diverse combinations of genetically predetermined code words that form meaningful patterns in response to appropriate sensory stimuli. This hypothesis is somewhat analogous to the clonal selection theory of antibody diversity (Burnet, 1969) and obviates the necessity of postulating a chemical code other than that already existing in the genetic apparatus. Therefore, in the present study, neuronal chromatin was isolated from the cerebral cortices of trained and control rats, and chromatin template activity and melting profile were assayed as in vitro parameters of genetic activity.

\section{METHODS}

For each experiment, 40 female SIV-50 rats were weaned at 21 days of age and were evenly distributed between experimental and control groups. Experimental animals were kept for 7 days in a "superenriched environment" designed to provide a maximum of social and intellectual stimulation while at the same time requiring true learning for survival (Kuenzle \& Knüsel, 1974). Thus, in order to get access to food and water, animals were forced to balance on ropes, select and open appropriate gates, and traverse a maze placed in front of the food dispenser. The training program was a short version of the one described previously. Control animals were housed in groups of 10 in plastic cages $(55 \times 30 \times 18 \mathrm{~cm})$ with free access to food and water. At the end of the training period, experimental and control rats were killed by decapitation. Neuronal nuclei were isolated from 20 pooled cerebral cortices (Knüsel, Lehner, Kuenzle, \& Kistler, 1973) and were used as a source of chromatin (Bonner, Chalkley, Dahmus, Fambrough, Fujimura, Huang, Huberman, Jensen, Marushige, Ohlenbusch, Olivera, \& Widholm, 1968). Chromatin melting profiles were determined as described in the legend to Figure 2. Chromatin template activities were assayed as described by Bonner et al. (1968), using DNA-dependent RNA-polymerase from E.coli (382 units/mg; Sigma Chemical Company, St. Louis, Missouri), unlabeled nucleoside triphosphates (Calbiochem, Lucerne, Switzerland) and $\left[5-{ }^{3} \mathrm{H}\right]$-uridine triphosphate (specific activity, $10.0 \mathrm{Ci} / \mathrm{mmol}$; Radiochemical Centre, Amersham, U. K.); incorporation of label into acid insoluble material was measured as described by Bollum (1968) and DNA was determined according to Burton (1968).

\section{RESULTS}

\section{Template Activity}

Seven experiments were performed using five units of exogenous RNA polymerase and a template concentration equivalent to 5 micrograms DNA/250 microliters. The incorporation of radioactive uridine into acid insoluble material was $780 \pm 50$ counts/min (mean \pm SD) when chromatin from trained rats was used as a template as compared with $830 \pm 60$ counts/min for the controls. Thus, the difference was not statistically significant. A more detailed analysis was performed in two further experiments using 10 units of RNA polymerase and increasing amounts of chromatin (Figure 1). Chromatin preparations from both experimental and control animals were used to plot template activity against DNA concentration. In both instances, the resulting curves were virtually identical.

\section{Chromatin Melting Profile}

Two melting experiments each were conducted with chromatin obtained from trained and control animals. The means are represented in Figure 2. The melting profiles from both types of chromatin were almost superimposable, and the melting temperatures $\left(T_{m}\right)$ and hyperchromicities were essentially identical.

\section{DISCUSSION}

Measurements of chromatin template activity are commonly used to assess the degree of gene activation in various organs. For instance, template activity of liver chromatin increases following partial hepatectomy (Thaler \& Villee, 1967), and a similar effect 


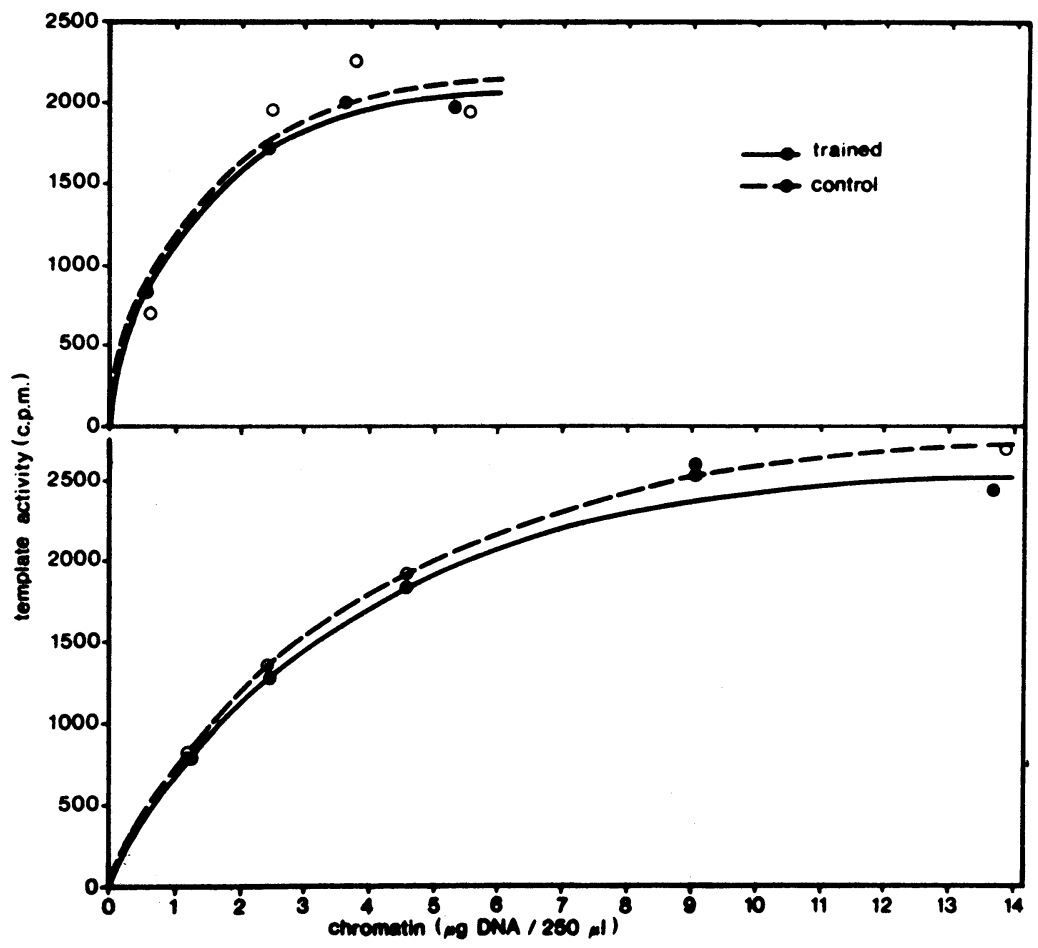

Figure 1. Template activity of chromatin prepared from neuronal nuclei of trained and control rats. Ten units of exogenous RNA poly merase were used in each assay. Points represent means of duplicate determinations. Each plot was obtained from a single chromatin preparation obtained by pooling nuclei from 20 rats.

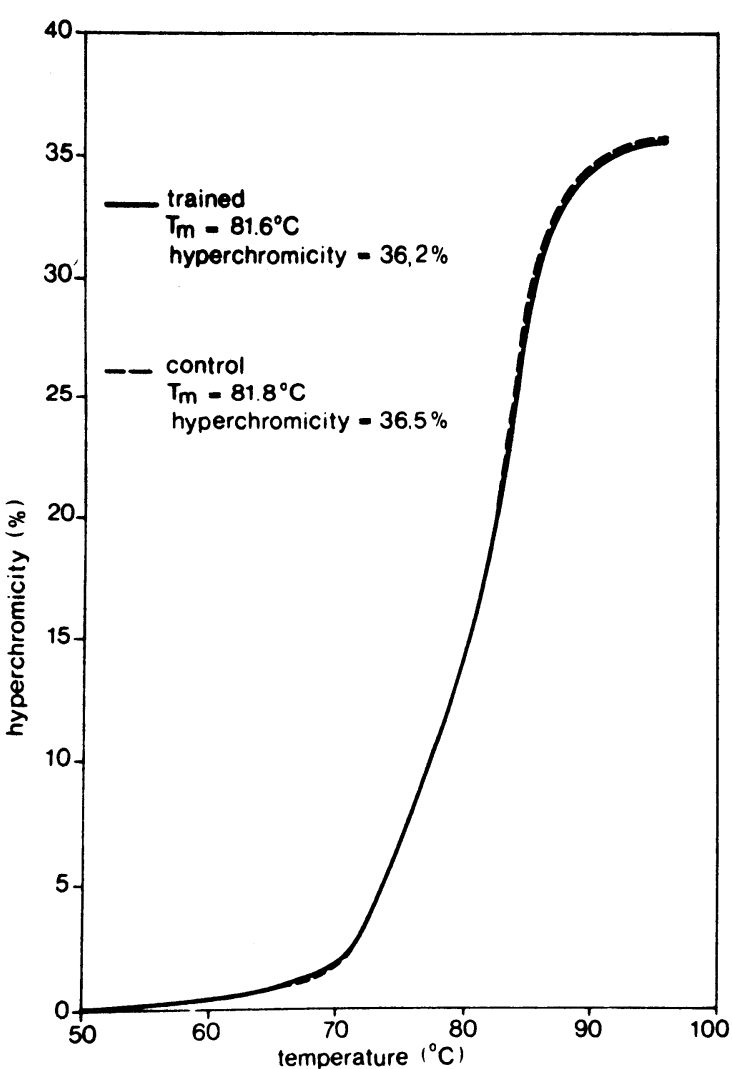

Figure 2. Melting profiles of chromatin prepared from pooled neuronal nuclei of trained and control rats. Each plot represents the mean of two independent experiments. Chromatin melting profiles were recorded at a starting $O D_{260}$ of .2 in $.01 \mathrm{M}$ Tris-HCl, pH 8.0, using a Beckman Acta III spectrophotometer. Temperature increase, $1^{\circ} \mathrm{C} / \mathrm{min}$. is produced by hydrocortisone (Dahmus \& Bonner, 1965). Estrogen treatment of ovariectomized rats also entails gene activation and enhances template activity of uterine chromatin (Barker \& Warren, 1966). Melting profiles of repressed and active chromatin from lymphocytes differ in shape, and the active species displays lower values of $T_{m}$ and hyperchromicity (Frenster, 1965).

In our experiments, cortical neurons from trained and control animals proved to contain chromatin of indistinguishable template activity and melting profile. This indicates that either gene activation in trained animals is too low for detection or that gene activation is not the basis of memory and learning.

\section{REFERENCES}

Barker, K. L., \& Warren, J. C. Template capacity of uterine chromatin: Control by estradiol. Proceedings of the National Academy of Sciences, 1966, 56, 1298-1302.

Bollum, F. J. Filter paper disk techniques for assaying radioactive macromolecules. In $S$. P. Colowick and $N$. $O$. Kaplan (Eds.), Methods in enzymology (Vol. 12B). New York: Academic Press, 1968. Pp. 169-173.

Bonner, J. Molecular biological approaches to the study of memory. In J. Gaito (Ed.), Macromolecules and behavior (2 nd ed.). New York: Appleton-Century-Crofts, 1972. Pp. 360-366.

Bonner, J., Chalkley, G. R., Dahmus, M., Fambrough, D., Fujimura, F., Huang, R. C. C., Huberman, J., Jensen, R., Marushige, K., Ohlenbusch, H., Olivera, B., \& Widholm, J. Isolation and characterization of chromosomal nucleoproteins. In S. P. Colowick and N. O. Kaplan (Eds.), Methods in enzymology (Vol. 12B). New York: Academic Press, 1968. Pp. 3-65.

Burnet, F. M. Self and not-self. Cambridge: Cambridge University Press, 1969.

Burton, K. Determination of DNA concentration with diphenylamine. In S. P. Colowick and N. O. Kaplan (Eds.), Methods in enzymology (Vol. 12B). New York: Academic Press, 1968. Pp. 163-166.

Dahmus, M. E., \& Bonner, J. Increased template activity of liver chromatin, a result of hydrocortisone administration. Proceedings of the National Academy of Sciences, 1965, 54, 1370-1375.

Frenster, J. H. Nuclear poly anions as de-repressors of sy nthesis of ribonucleic acid. Nature (London), 1965, 206, 680-683.

Glassman, E. The biochemistry of learning. Annual Review of Biochemistry, 1969, 38, 605-646. 
Knüsel, A., Lehner, B., Kuenzle, C. C., \& Kistler, G. S. Isolation of neuronal nuclei from rat brain cortex. Journal of Cell Biology, 1973, 59, 762-765.

Kuenzle, C. C., \& Knüsel, A. Mass training of rats in a super-enriched environment. Physiology and Behavior, 1974, $13,205-210$.
Thaler, M., \& Villee, C. A. Template activites in normal, regenerating, and developing rat liver chromatin. Proceedings of the National Academy of Sciences, 1967, 58, 2055-2062.

(Received for publication March 25, 1975.) 